\title{
Impact of Event Tourism in a Tourist Destination Quality of Experience - Case of the Sarajevo Film Festival
}

\author{
Elvir Čizmić, Amra Čaušević* \\ School of Economics and Business Sarajevo, Sarajevo University, Bosnia-Herzegovina
}

Copyright $\subset 2017$ by authors, all rights reserved. Authors agree that this article remains permanently open access under the terms of the Creative Commons Attribution License 4.0 International License

\begin{abstract}
The aim of the research is to determine how the Sarajevo Film Festival affects the image of the city of Sarajevo and the satisfaction of tourists at tourist destination city of Sarajevo, as well as to establish the relationship between the Sarajevo Film Festival and tourist perception of Sarajevo. The study used a quantitative approach to research, which included data collection through surveys (Face to Face) of respondents, with the use of a questionnaire, specifically created for this study. The population covered by this research are foreign tourists (people who are not citizens of Bosnia and Herzegovina), who visited Sarajevo in the period of the Sarajevo Film Festival (15-23. August 2014), as well as in the period of one month before and after it was held (July and September 2014).
\end{abstract}

Keywords Event Tourism, Event Management, The Image of a Tourist Destination, The Perception of a Tourist Destination

\section{Introduction}

Throughout the period of its existence, tourism is a reflection of the human tendency to move, it has seen many modifications of its segments, striving to adapt to changes in the tourism market, and mostly to changes in the requirements and needs of tourists. Event tourism is one of the youngest but also the most promising forms of tourism, whose expansion began in the last decades of the twentieth century.

Events are there as part of a tourist-product, with greater or lesser importance and influence on the destination, but their commercialization was initiated by the active interest of the participants of tourism and entire economies for studying of this field, with the aim of increasing economic and other benefits that the community realizes.

A number of conclusions that have been reached by studious analysis of tourism events have shown that the right approach to planning and organizing events can improve not only economic effects but also the impact that these events have on the formation of the image of the destination.

We can say for Sarajevo, as micro-destination within the tourist destination of Bosnia and Herzegovina, is a typical example of tourist locations for which event tourism represent a market segment and the driver of the overall development of tourism, as well as a key element in the formation of the image and positioning on the tourist market.

Sarajevo Film Festival represents the vision of the tourist offer, in which the content of the festival itself is a tourist value. The festival is also a supplement of tourist content in the city. The festival can be an important motivator for travel, and event tourism is one of the fastest growing segments of the tourism industry. This is conditioned by the ability of events to help the level of tourist attractiveness, media coverage and the promotion of the city and the destination for future visitors.

\section{Literature Overview}

Tourism is a complex phenomenon which encapsulates a varying number of services and processes. It is not an industry or a sector in the traditional sense, rather it is an economic activity that runs through all of the society involving very different and varied sectors pushed forward by market forces, controlled by regulatory framework and governed by general economic conditions. In many countries and regions, tourism is significantly important to the economy because it attracts tourists who bring spending power. For many regional economies, tourism can bring about an encouraging response to the regional development considering its positive influence on regional employment and income. According to World Travel and Tourism Council (WTTC), travel and tourism is an important economic activity in most countries around the world. It has a direct as well as a significant indirect and induced economic impact [1].

Place marketing has become commonplace throughout Europe, North America and elsewhere. Competition between cities to create a positive image to attract important 
stakeholders, including consumers, investors and tourists, is becoming increasingly intense. The influence of image on destination choice process has been studied by various authors and it is widely acknowledged that the image of cities can influence perceptions, choice, behaviour and satisfaction of customers, investors or visitors. City image is generally referred to as the overall impression that a city creates in the minds of various target groups, including its functional and symbolic elements. It encompasses the city's physical attributes, services, attractions, name, logo, reputation, and the benefits that those provide to the target groups. A city's image can be enhanced or changed; and the deliberate use of various strategies to enhance or change a city's image by marketers is often called city branding or city imaging [2].

City mayors and decision-makers have, for decades, been working to meet the strategic challenge of branding cities in order to attract tourists. Despite the vast amount of research invested in this area, in practice the method for branding cities to gain more tourist volume still seems to be an enigmatic process. Many researchers have focused on large-scale festivals - mainly sporting events - as ways to draw tourists and have ignored small-scale events for small cities [3].

Over the years, city branding researchers and tourism scholars have worked to identify the right city branding or re-branding strategy in order to attract more local and mainly foreign tourists. Although this single right strategy for branding or re-branding a city for attracting tourists remains elusive, researchers all agree that the city positioning decision is a crucial phase in determining the success of this strategic process [4].

City planners and decision-makers invest a lot of energy and money in branding/re-branding their cities, based on events and festivals. In order to do this well, they must know the opportunities and limitations of each city positioning type. Essentially, city planners and decision-makers can base their events on four main themes: sports, famous people, films, and culture. Cities that wish to host mega events, which attract tourists from all over the world, should view these as a long-term investment that builds a positive image in tourists' minds. The events are merely the first stage of a program that will continue to draw tourists for many years after the initial mega event. Cities that wish to host annual international events, which attract tourists from all over the world to the same city every year, should work on the assumption that the key to the success of this type of city positioning is the ability to create strong linkage between the city's character and assets (physical and human) and the specific event/festival. City planners hosting medium-sized events, which are held in many cities all over the globe but attract mainly domestic visitors year after year and all year round, should ensure that their cities become more meaningful in their own country and play a powerful economic and/or tourist function in their country. In contrast, city planners and decision-makers who wish to host minor events, which characterise small cities that wish to differentiate themselves from neighbouring cities, should target the local citizenry and work to boost their pride in their city and celebrate their traditions and customs. Based on the high level of competition of cities all over the world, undoubtedly, city leaders, planners and decision-makers will keep investing in promoting a positive image for their cities and events and festivals will continue to be part of cities' lives and spirit [3].

The attractive element of tourism destination is its tourism product, as which an organized event which serves to attract tourists can be considered, creating the image and competitiveness of the destinations. Organized events can affect the perception of foreign tourists on the image of the city where it took place. In addition to the increase in tourist visits at the organized event, the event itself may attract media attention and increase access to the destination that enhances the reputation (image) of the host city or tourist regions. Media exposure of successfully organized events may illustrate the quality of skills, innovation and achievements of the host of the destination in organizing the event [5].

Countries and local communities host mega sport events such as the Olympics or the FIFA World Cup with expectations to bring benefits such as economic uplift, new job creation, image improvement, promotion of domestic products in the global marketplace, attraction of foreign investment, increase in tourism, acceleration of urban development, infrastructure improvement, accumulation of event management expertise, enhancement of the national team's performance, stimulation of sports participation, social unification, enhancement in national pride, and introduction of sustainable development [6].

Among these benefits, improvement of the host's image is central because it is the foundation of various other outcomes including increased tourist visitation and a stronger brand of the host country and its products, which drive the bulk of economic gains. According to an economic impact analysis on the 2012 London Olympics, increased tourist visits and related revenues were expected to comprise from half to three-quarters of the economic legacy [7].

Two related streams of research examine the host country's image improvement: One focuses on destination image (i.e., the host country or local community's image as a tourism site) and the second focuses on country image (i.e., overall image of the country). From the tourism perspective, many studies exist regarding the impact of mega sport events on destination image that present results of improved destination image after hosting sport events. Host countries are commonly "optimistic" about their respective image improvement, which is the primary justification for funding the sport event. However, this "optimism" needs to be tempered with realism as several studies also demonstrate mixed or no impact on the host's destination image [8].

Results of empirical research conducted in March 2011, in which data was collected from foreign tourists in Shanghai, 
showed that the effect of awareness of sports events on the overall image of the destination is statistically significant and negative. The result of that awareness of the great sporting events negatively affects the quality of the experience, as well as the overall image of the destination which is contrary to the existing literature [2]. Most other conducted research has shown that events positively affect the image of the destination.

On the other hand, from the international marketing perspective, host countries commonly utilize mega sport events believing they are effective marketing outlets for enhancing the country's image and thus the brand of the host country's product. However, there is a void of research in the sport context leaving the claimed benefits unverified. Further research addressing potentially unjustified optimism on the benefits of destination and country image improvement is imperative, but challenging due to various methodological issues. One of the critical issues in image change studies is the predominant use of cross-sectional design, which raises concerns about internal validity. A pre-post design improves the quality of evidence regarding the impact of a mega-sport event. Although studied in parallel, destination and country images are similar and interrelated constructs based on shared characteristics (e.g., overlapping research topics, correlated marketing goals, and shared theoretical base). A cross-examination of the two images is necessary to advance research in destination and country image (for clearer understanding through comparison, cross-application of knowledge, and availing integrative marketing). However, no comprehensive research exists on the two images with respect to mega sport events; as a result, an empirical study laying out the foundation for interdisciplinary research and integrated image marketing is in order. In this sense, it is necessary to conduct an empirical research to understand the relationship between two images and their connection to relevant behavioral intentions [9].

The another type of city positioning beside mega events is via medium-sized events, which are held in many cities all over the globe but attract mainly local travellers every year and all year round. This positioning strategy ensures that cities become more meaningful in their own country and play a more powerful economic and/or tourist function. Marathons, which are hosted by cities that are not capital cities, mainly attract locals and visitors from nearby cities and local countries. Also, music festivals and other cultural events bring tourists from neighbouring cities, and on some occasions, from neighbouring countries. The city of Vienna is known as the premier European city with music festivals all year long [10]. Tel Aviv draws young tourists to the Middle East thanks to its reputation of a city that never sleeps [11]. In order to promote medium-sized events, city decision-makers should use national media and acquire local sponsorships from top national branded products and services.

The highest attendance in city of Sarajevo is in the summer months, especially during the Sarajevo Film Festival.
The largest film festival in Bosnia and Herzegovina and in the region is the Sarajevo Film Festival, which attracts many tourists, both domestic and tourists around the world. The Sarajevo Film Festival is one of the most prominent film festivals in the Southeast Europe. It is held every year since 1994 in Sarajevo and has average visit of about 100,000 film fans. It is a leading film festival in the region, recognized by both film professionals and the general public. High-quality programs, strong industry segment, educational and networking platform for young film makers and the presence of representatives of the film industry, film makers and media representatives, with an audience exceeding 100,000 people, are a confirmation of the Sarajevo Film Festival status. The image of the City of Sarajevo and all of Bosnia and Herzegovina can be improved through the Sarajevo Film Festival [12].

\section{Methodology and Research Results}

The paper used a quantitative approach to research, which included data collection through surveys (Face to Face) of respondents, with the use of a questionnaire, specifically created for this study.

The questionnaire is divided in four sections. All sections of the questionnaire mainly include questions that are fit using a Likert scale from one (1) to five (5).

The study used two identical versions of the questionnaire - one in the Bosnian language (which was applied when interviewing foreign tourists from Croatia and Serbia, as well as tourists from other countries who have stated that they prefer this version of the questionnaire) and one in English (for foreign tourists who do not understand the Bosnian language, and understand the English language). The identity of these questionnaires was provided by the translation of the questionnaire from Bosnian language into English and by making a back-translation, after which their final adjustment was made.

Survey instrument - the questionnaire was taken from already conducted similar studies, where it confirmed its reliability.

After collecting data and its input in the SPSS base and preparation for processing, the test of internal consistency of each of the sections that measure experience and perception of Sarajevo and the Sarajevo Film Festival was carried out by calculating Cronbach Alpha coefficients. The calculated coefficients for each section are in the table below.

Table 1. Cronbach Alpha coefficients for each section

\begin{tabular}{|c|c|}
\hline Section & Cronbach's Alpha \\
\hline Quality of the experience of the visit & .916 \\
\hline Rating of the Sarajevo Film Festival & .940 \\
\hline Impact on the change in perception of Sarajevo & .851 \\
\hline Perception of Sarajevo as a tourist destination & .840 \\
\hline
\end{tabular}

As it can be seen, Cronbach alpha coefficients were all 
above 0.7 , which confirms the high reliability of the measuring instrument.

The sample size for this survey was 400 respondents (foreign tourists) randomly chosen - 200 foreign tourists who visited Sarajevo during the Sarajevo Film Festival (15-23. August 2014) and 200 who came in the period of one month before and after its occurrence (100 foreign tourists who visited Sarajevo in July and 100 foreign tourists who visited Sarajevo in September 2014). For the selection of the respondents the classical method of interception was used.

The research data was analyzed separately for two target groups of respondents, that is, for (1) foreign tourists who visited Sarajevo during the Sarajevo Film Festival and (2) foreign tourists who visited Sarajevo in the period from one month before and after its occurrence. After that, a comparison was made of these data, and an analysis was made for each of the two examined groups.

To achieve scientific relevance, during the analysis and interpretation of the obtained data, descriptive statistics and tests of statistical significance were used. In this way, the validity of the hypothesis was verified.

\subsection{The Quality of the Experience of the Visit}

In this section, the goal was to investigate the perceived quality of accommodation in Sarajevo and whether the occurrence of the Sarajevo Film Festival affected the perceived quality. In order to show the differences in the quality of the visit before, during and after the festival, an analysis was made by determining the arithmetic mean. Arithmetic means were compared in groups between visitors who visited Sarajevo during and before / after the Sarajevo Film Festival. Also, it was compared to the total and the arithmetic mean of all the elements.

The total average satisfaction in all elements is slightly higher among visitors who visited Sarajevo before and after the festival, but for those who stayed in Sarajevo during the Festival. In order, however, eliminate the differences that are insufficiently large to be statistically significant, an appropriate statistical test was conducted. Since this is the data which does not have a normal distribution and ordinal variables, the nonparametric Mann-Whitney $U$ test was the most acceptable for this analysis.

Table 2. Quality of the visit by the time the visit and the accompanying results of the Mann Whitney U test

\begin{tabular}{|c|c|c|c|c|}
\hline & \multicolumn{2}{|c|}{ Time of visit } & \multirow{3}{*}{$\begin{array}{c}\text { Difference } \\
\text { (SFF - July and } \\
\text { September) }\end{array}$} & \multirow{3}{*}{$P$ value } \\
\hline & $\begin{array}{c}\text { July and } \\
\text { September }\end{array}$ & SFF & & \\
\hline & Mean & Mean & & \\
\hline Feeling (personal) of safety and security & 4,31 & 3,97 & $-0,33$ & 0,005 \\
\hline Possibility of easy arrival (transport accessibility) & 3,84 & 3,92 & 0,08 & 0,375 \\
\hline Local transport services (bus, tram, trolleybus, taxi ...) & 3,73 & 3,62 & $-0,11$ & 0,096 \\
\hline Tourist signs & 3,88 & 3,78 & $-0,10$ & 0,347 \\
\hline The quality of accommodation (hotel, motel, accommodation ...) & 4,39 & 4,08 & $-0,30$ & 0,000 \\
\hline The beauty of nature and landscape & 4,49 & 4,22 & $-0,27$ & 0,004 \\
\hline Overall cleanliness & 3,98 & 4,02 & 0,04 & 0,668 \\
\hline Climate & 4,02 & 4,11 & 0,09 & 0,276 \\
\hline $\begin{array}{l}\text { The kindness of the population and people working in tourism (tourism } \\
\text { workers) }\end{array}$ & 4,37 & 4,30 & $-0,07$ & 0,407 \\
\hline Opening hours of banks, shops and restaurants & 4,33 & 4,28 & $-0,05$ & 0,546 \\
\hline The diversity of cultural, historical and sports facilities & 4,06 & 4,06 & 0,00 & 0,661 \\
\hline The diversity of health facilities & 3,66 & 3,94 & 0,29 & 0,005 \\
\hline Gastronomic offer & 4,13 & 4,24 & 0,11 & 0,127 \\
\hline Options for shopping & 4,19 & 4,26 & 0,07 & 0,534 \\
\hline Options for relaxing and recreation & 4,18 & 4,19 & 0,01 & 0,991 \\
\hline Entertainment (social activities with friends, nightlife, etc.) & 4,09 & 4,36 & 0,27 & 0,005 \\
\hline Offer of cultural and other events & 4,02 & 3,92 & $-0,11$ & 0,286 \\
\hline The general image of Sarajevo as a tourist destination & 4,25 & 4,20 & $-0,05$ & 0,435 \\
\hline Comeing to Sarajevo has fulfilled my expectations & 4,46 & 4,27 & $-0,19$ & 0,016 \\
\hline
\end{tabular}


Only entertainment ( $\mathrm{p}$ value 0.005 ) and the variety of health facilities ( $p$ value 0.005 ) as a component of the quality of the visit had positive difference which is statistically significant. On the other hand, coming to Sarajevo has fulfilled expectations ( $p$ value 0.016), the beauty of landscapes and nature (0.004), quality of accommodation $(0,000)$ and the feeling of safety and security $(0,005)$ had statistically significant negative difference, which means that visitors in July and September were more satisfied with these elements, but visitors during the Sarajevo Film Festival.

\subsection{Rating of the Sarajevo Film Festival}

If we analyze the experience, that is, satisfaction with specific elements of the Sarajevo Film Festival, the highest average score of a general experience of the Sarajevo Film Festival can be seen. Rating of 4.24 is very close to the maximum score of 5, which means that visitors are completely satisfied.

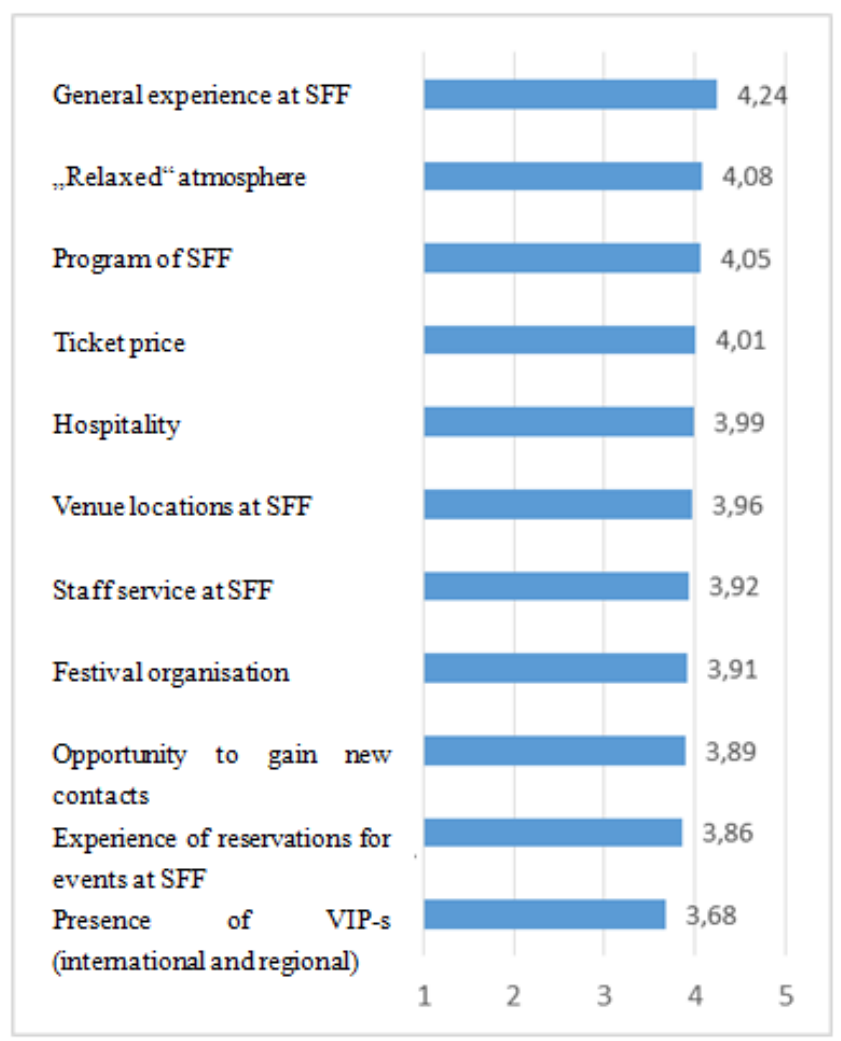

Graph 1. Satisfaction with the Sarajevo Film Festival by elements scale

In addition to the general experience, the average rating of 4 and higher received the following elements: relaxed atmosphere (4.08), Program of Sarajevo Film Festival (4.05) and ticket prices for Sarajevo Film Festival (4.01), and close to the average rating of 4 received: Hospitality (3.99) and venue of the festival (3.96).
The visitors were least satisfied with the presence of famous personalities (3.68), experience with ticket reservations (3.86), the ability to gain new contacts (3.89), the festival organization (3.91) and staff service at Sarajevo Film Festival (3.92). However, it is important to note that the lowest rating is above 3.5, which is the middle grade and is closer to the positive than the negative one.

Considering that the lowest score is 3.68 , it can be concluded that visitors are satisfied with all elements of the Sarajevo Film Festival, and are most satisfied with the complete impression of the Festival.

\subsection{Influence on Changing the Perception of Sarajevo}

After arriving in Sarajevo, most of the visitors experienced a change of the perception of Sarajevo to better. There are more of those who experienced a change of the perception in the group that visited Sarajevo in July and September.

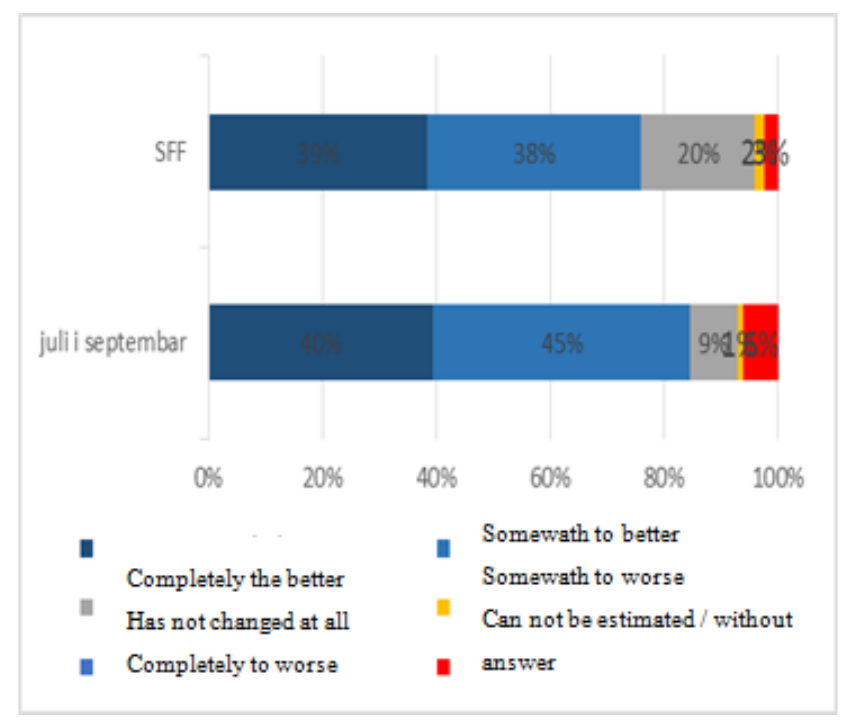

Graph 2. Change of Perception

It is important to highlight a large share, four out of ten, of those whose perceptions have changed completely to a better (most positive change). This is the case for groups of tourists, almost equally, 39\% of tourists visiting Sarajevo during the SFF holding and $40 \%$ of tourists visiting Sarajevo in July and September. Very few people have said that perception has changed to the worse.

Next to the question about change of perception, tourists pointed out how many the offered elements influenced change of their perception. As seen in the following table for tourists who were in Sarajevo during the Sarajevo Film Festival, and had changed their perception of Sarajevo, the rich variety of cultural and other contents (grade 4.10), traffic accessibility (4.05) and the accommodation offer (4.02) had the most impact on them. The change in perception has been affected to a lesser extent by: meetings with people (rating 4,01), city appearance $(4,00)$, entertainment and leisure $(3,97)$, feeling of safety $(3,91)$ and Sarajevo Film Festival 3.79). 
Table 3. The effect of the change of perception of Sarajevo

\begin{tabular}{|c|c|c|c|}
\hline \multicolumn{2}{|c|}{ July and September } & \multicolumn{2}{c|}{ SFF } \\
\hline Appearance of the city & 4,16 & $\begin{array}{c}\text { The rich variety of cultural, } \\
\text { historical, medical and sports } \\
\text { facilities }\end{array}$ & 4,10 \\
\hline Meetings with people & 3,93 & Traffic accessibility & 4,05 \\
\hline $\begin{array}{c}\text { The rich variety of cultural, historical, medical and sports } \\
\text { facilities }\end{array}$ & 3,91 & Other offers & 4,02 \\
\hline Feeling of security & 3,82 & Meetings with people & 4,01 \\
\hline Entertainment and leisure & 3,69 & Appearance of the city & 4,00 \\
\hline Traffic accessibility & 3,62 & Entertainment and leisure & 3,97 \\
\hline Other offers & 3,51 & Feeling of security & 3,91 \\
\hline Sarajevo Film Festival & 2,71 & Sarajevo Film Festival & 3,79 \\
\hline
\end{tabular}

Sarajevo Film Festival has affected the change in perception of festival tourists with a grade of 3.79. Rating of 3.79 is close to the assessment of 4 , which means that the festival influenced the change of perception (often better).

\subsection{Perception of Sarajevo as a Tourist Destination}

At the end of the questionnaire, attitudes regarding Sarajevo as a tourist destination were tested. There are more claims that visitors agree at during the Festival (seven), than those that match visitors of Sarajevo by the Festival.

In this case, the table below lists elements that statistically differ significantly between these two samples. The claims that are more in line with the visitors during the Sarajevo Film Festival are bold, while claims of tourists surveyed in July and September are in italic, and have a statistically significant difference between these two samples, established by Mann Whitney U test, used as well as in the evaluation of the quality of tourist experience.

With the following statements, the visitors who visited Sarajevo during the Sarajevo Film Festival were more consistent, and statistically significant are: I think most people (who are not from $\mathrm{BiH}$ ) have a positive opinion about Sarajevo (as a tourist destination) - grade 3,99, I think Sarajevo is a popular tourist destination (grade 3.80), I think that the Sarajevo Film Festival's existence / occurrence significantly improves Sarajevo's tourist offer (4.01), Sarajevo has more advantages than similar European cities (3.81), When I feel a need for relaxing / travel abroad I only visit Sarajevo (3.20) and I like Sarajevo more than other tourist cities (3.66). With the claim that staff in Sarajevo (waiters, bank employees, retailers etc.) are friendly to the guests (grade 4,41), tourists who visited Sarajevo in July and September agree more to, and it is statistically significant, established by Mann Whitney U test.

With six statements related at opinions about Sarajevo as a tourist destination, the visitors who visited Sarajevo during the Sarajevo Film Festival were more statistically significant. Tourists believe that the existence / occurrence of the Sarajevo Film Festival significantly improve the tourist offer of Sarajevo. Overall, tourists who visited
Sarajevo during the Festival have a positive opinion and image of Sarajevo as a tourist destination. Only with one statement do visitors who visited Sarajevo in July and September agree more than visitors who visited Sarajevo during SFF.

\section{Testing of Research Hypotheses}

The hypothesis and results of the tests are presented below, which are already shown in the research results.

H1: The presence at the Sarajevo Film Festival influences the tourist's satisfaction with the tourist destination of the city of Sarajevo.

Analyzing the opinions regarding Sarajevo as a tourist destination, it can be concluded that there are more claims that visitors who visited Sarajevo during the Festival agree at. With the following statements, the visitors who visited Sarajevo during the Sarajevo Film Festival were more consistent and statistically significant: I think most people (who are not from $\mathrm{BiH}$ ) have a positive opinion about Sarajevo (as a tourist destination) - grade 3,99, I think Sarajevo is a popular tourist destination (grade 3.80), I think that the Sarajevo Film Festival's existence / occurrence significantly improves Sarajevo's tourist offer (4.01), Sarajevo has more advantages than similar European cities (3.81) When I feel a need for relaxing / travel abroad I only visit Sarajevo (3.20) and I like Sarajevo more than other tourist towns (3.66). With the claim that staff in Sarajevo (waiters, bank employees, retailers etc.) are friendly to the guests (grade 4,41), tourists who visited Sarajevo in July and September agree more to, and it is statistically significant, established by Mann Whitney U test.

With six statements related at opinions about Sarajevo as a tourist destination, the visitors who visited Sarajevo during the Sarajevo Film Festival were more statistically significant. Tourists believe that the existence / occurrence of the Sarajevo Film Festival significantly improve the tourist offer of Sarajevo. Overall, tourists who visited Sarajevo during the Festival have a positive opinion and image of Sarajevo as a tourist destination. 
Table 4. Perception of Sarajevo as Tourist Destinations and Results Mann Whitney In the test

\begin{tabular}{|c|c|c|c|}
\hline & July and September & SFF & P value \\
\hline $\begin{array}{c}\text { I think most people (who are not from BiH) have a positive opinion of } \\
\text { Sarajevo (as a tourist destination). }\end{array}$ & 3,53 & 3,99 & 0,000 \\
\hline Sarajevo (as a tourist destination) has a unique image. & 4,18 & 4,15 & 0,712 \\
\hline I think Sarajevo is a popular tourist destination. & 3,33 & 3,80 & 0,000 \\
\hline $\begin{array}{c}\text { I think the existence / occurrence of the Sarajevo Film Festival significantly } \\
\text { improves Sarajevo's tourist offer. }\end{array}$ & 3,29 & 4,01 & 0,000 \\
\hline Staff in Sarajevo (waiters, bank employees, retailers etc.) are friendly to guests. & 4,41 & 4,13 & 0,002 \\
\hline Sarajevo is one of the cities I'd rather visit. & 3,78 & 3,85 & 0,771 \\
\hline Sarajevo offers more advantages than similar European cities. & 3,19 & 3,81 & 0,000 \\
\hline When I feel the need for vacation / traveling abroad I visit only Sarajevo. & 1,70 & 3,20 & 0,000 \\
\hline I like Sarajevo more than other tourist towns. & 3,02 & 3,66 & 0,000 \\
\hline
\end{tabular}

Accordingly, we can conclude that the attendance at the Sarajevo Film Festival influences the tourist's satisfaction with the tourist destination of the city of Sarajevo and thus the first hypothesis is accepted.

H2: Visitors to the Sarajevo Film Festival have a more positive perception of Sarajevo as a tourist destination compared to other tourists.

After arriving in Sarajevo, most of Sarajevo's visitors changed their perception for the better. Tourists visiting Sarajevo during the Sarajevo Film Festival changed the perception of Sarajevo to the best (39\%), while this case was in $40 \%$ of tourists who visited Sarajevo in July and September. It can be concluded that both groups of tourists have almost altered the perception of Sarajevo completely to the better. Very few people have said that their perception has changed to the worse.

The change of perception of tourists who visited Sarajevo during the Sarajevo Film Festival was largely affected by the rich variety of cultural, historical, health and sports content (grade 4.10), traffic accessibility (rating 4.05) and other offers $(4,02)$. The changed of perception of Sarajevo of tourists visiting Sarajevo in July and September was most influenced by the city's appearance (rating 4,16), meeting people (rating 3,93) and the rich variety of cultural, historical, health and sports facilities $(3,91)$.

In both groups of tourists, the Sarajevo Film Festival had the least influence to change of perception of Sarajevo, with a score of 3.79 for festival tourists, and a score of 2.71 for tourists from July and September. In the case of tourists who were not in Sarajevo during the festival, this result was expected because they had no experience with the Festival. For festival tourists, the score of 3.79 is close to 4 , which means that the festival has influenced the change of perceptions (most often the better), but this rating should be seen in the context of other elements that have more impact than the Sarajevo Film Festival itself. The second hypothesis is not accepted by the above data.

H3: The Sarajevo Film Festival has a positive effect at overall quality of experience of stay in Sarajevo in foreign tourists.

To assess the quality of stay, 19 variables were determined by which to measure how many tourists were satisfied with each of the 19 elements of quality of tourist visit. The positive difference between the average score of the elements between the respondents surveyed during the Sarajevo Film Festival and those who visited Sarajevo past festivals have emerged with the following elements: the possibility of easy arrival (transport accessibility) score of 3.92, the overall cleanliness (4.02), climate (4.11), the rich variety of cultural, historical and sports facilities (4.06), the variety of health facilities (3.94), cuisine (4.24), shopping opportunities (4.26), opportunities for relaxing and recreation (4.19), entertainment (social activities with friends, nightlife, etc.), rating 4.36 .

In the following elements negative differences have been found, which means that with these elements were more satisfied visitors who have not visited Sarajevo during the Sarajevo Film Festival: a sense of (personal) safety and security (4.31), local transport (bus, tram, trolleybus, taxi) 3.73 rating, tourist signalization (3.88), quality of accommodation (hotel, motel, accommodation) score of 4.39 , the beauty of nature and landscapes (4.49), courtesy of the population and people working in tourism (tourism workers) 4.37 rating, working hours of banks, shops and restaurants (4.33), offer of cultural and other events (4.02), the overall image of Sarajevo as a tourist destination (4.25), visiting Sarajevo has met my expectations ( 4.46).

The total average satisfaction in all elements is slightly higher among visitors who visited Sarajevo before and after the festival, but for those who visited Sarajevo during the festival.

Testing the variables which represent the quality of stay in Sarajevo during and before / after the Sarajevo Film Festival, and the satisfaction of all the elements of quality of the stay, significant differences were observed. The Mann-Whitney U test was applied, taking into account the type of data and research goals. The test has proved that satisfaction at six out of 19 elements of satisfaction of stay has shown significantly differences. These are: a sense of personal safety (test result -0,005), quality of accommodation (0000), the beauty of nature and landscapes (0004) Entertainment (0005), the variety of health facilities 
(0005) and fulfillment of the expectations of the visit (0016).

Since the only difference is significantly different to only one third of the elements, we cannot accept this hypothesis, but we can partially use this report to obtain a complete picture of the experience of tourists to Sarajevo.

H4: Sarajevo Film Festival significantly improves tourist offers of city of Sarajevo.

Analyzing opinions concerning Sarajevo as a tourist destination, there are more assertions to which visitors during the Festival agree to. With the statement "I think that the existence / occurrence of the Sarajevo Film Festival significantly improve the tourist offer of Sarajevo", and it is statistically significant established with Mann Whitney U test (0.000), visitors who visited Sarajevo during the Sarajevo Film Festival agreed to (score 4.01), unlike tourists who visited Sarajevo in July and September (3.29 rating). With this data, the fourth hypothesis is accepted.

\section{Discussion of Research Results}

After reviewing the research results and testing of hypothesis, many conclusions impose, depending from which angle problems are looked at.

The first and fourth hypotheses are accepted but the second and third hypotheses are not accepted. The rejection of the second and third hypotheses are in accordance with the results of an empirical survey conducted in March 2011, in which data were collected from foreign tourists in Shanghai. The study examines the negative impacts of mega sporting events on host cities and the relationship between negative impacts and the travel intentions of potential international tourists. Data were collected from Shanghai University students, who were asked about their international travel experiences, London Games awareness, the perceived negative impacts of the Games on London and their travel intentions during the London Games. The results have shown that the effect of awareness of a sporting event on the overall destination image is statistically significant and negative. The result that awareness of large sports events negatively affects the overall destination image is in contradiction with the existing literature [2].

The results of the research are also comparable with the results of the research conducted at the "Vize History and Culture Festival". To test the model, a study of local community festival in the Municipality of Vize, Turkey, was conducted. "Vize History and Culture Festival" is an annual festival which has been held since 2006 by the province municipality to develop economy, increase tourist attractiveness and improve civic pride and social cohesion. Celebrating and introducing local food traditions and eating habits, promoting Vize's historical and economic importance are among some other goals of the festival. Concerts, fashion parade, local food cooking competition, presentations underpinning the historical and archeological importance of
Vize, dance shows and commercial booths are some other events and features that take place in the festival.

Data for this study was collected during the 6th "Vize History and Culture Festival" festival held as a 4-day event between 21-24 of July, 2011. Population was defined as all visitors to the festival and random sampling was used, ensuring that all four days and all part of programs (day and night) were evenly covered. Seven hypotheses are defined for the study: H1: Festival area is positively associated with visitor's satisfaction; H2: Staff is positively associated with visitor's satisfaction; H3: Food is positively associated with visitor's satisfaction; H4: Souvenir is positively associated with visitor's satisfaction; H5: Informational adequacy is positively associated with visitor's satisfaction; H6: Convenience is positively associated with visitor's satisfaction; H7: Visitor's satisfaction is positively associated with visitor's loyalty. H1, H3, H6 and H7 were supported [13]. Research results are consistent with this research.

\section{Conclusions}

This research has multiple benefits both for the tourist offers, and the Sarajevo Film Festival.

When analyzing the quality and satisfaction of various elements of the visit or the tourist experience, the study found that the satisfaction was significantly different. However, it should not be considered as an absolute and total level, but by its elements. Visitors during the Festival are satisfied with the entertainment, while on the other hand the tourists who visited Sarajevo before and after the Festival were satisfied with cultural and other attractions, natural environment and the like.

In further aspects, it is worth to mention that experience significantly changes, in all groups of respondents, after visiting Sarajevo. The change in the vast majority of cases was positive. This change, the visitors during the festival were the most affected by the rich variety of cultural, historical and other events and the appearance of the city affected visitors of the Festival.

Tourists who have visited Sarajevo during the Sarajevo Film Festival have a positive opinion and image of Sarajevo as a tourist destination and considered that the existence / occurrence of the Sarajevo Film Festival significantly improve the tourist offer of Sarajevo.

If the overall research project would be observed and conclusions were drawn, this could be presented in the following theses:

- Sarajevo Film Festival is not a typical film festival, but a unique form that has organically grown in its years of formation.

This development has progressed intertwined with the development of the city in those years, so that the city and the festival often merged. What are the marketing 
implications of this is that the further development of the Sarajevo Film Festival, that is the development and design experience of visitors should be seen as a unique project. You cannot copy the models of other festivals (mostly made up of program and film stars - that make up the prestige dimension), but it is necessary to continue to develop its own model. This tells us is that research shows that visitors are often happier with the atmosphere, entertainment and elements that are not directly related to the Festival itself. However, although not directly related to the festival, alone the Sarajevo Film Festival should go out of its frames and design experience beyond the classic framework of the film festival.

- Experience of the visits Sarajevo Film Festival is inseparable from the experience of visiting the city.

The image of the city and the quality of visits Sarajevo Film Festival is often mixed with elements which are evaluated and compatible. Visitors are often confused and do not separate the experience of visiting the town and visit the Festival.

- Entertainment is a good element of the Festival, but we should not neglect the other elements.

The overall level of satisfaction is slightly higher for visitors who are visiting Sarajevo during the Festival. The elements whit which the visitors are the most satisfied with are the rich variety of cultural, historical and other attractions. This shows the potential development experience visit during the Sarajevo Film Festival in different directions, which does not include necessarily entertainment. In this case, it is possible to exploit the potential of the city and develop a range of different segments of tourists.

The research results can be a good guideline for the strategy of enriching the tourist offer of Sarajevo. Experiences and results of the research should be exploited in order to strategically enrich the offer of Sarajevo. They can be the basis for further development of the tourist offer - which will be an upgrade and enrichment of the current offer in order to provide more value to current and potential tourists. Sarajevo Film Festival has grown together with the city and is an inseparable part, and because of this it is more important to have a strategic approach to the design of other content based on marketing information and insights.

Research results may also be a good guide for designing other content. Whether it is content during the Festival or other periods of the year, they have to consider that the Sarajevo Film Festival has become in some segments bigger than the city itself. It is therefore important to use the research results to offer other contents and values in a way that it nourishes consistency and brings synergic effects to Sarajevo. The Sarajevo Film Festival is an unproductive film festival, which has a very large and important entertainment component. This component should be carefully nurtured within the comprehensive business model of tourist offer of the city as well as the Sarajevo Film Festival. This relationship between the content around and within the festival is now the result of organic growth, and in the future it should be part of the marketing strategy of all actors, primarily so that the current offer and value for tourists would not be undermined, and later on as the foundation for creating new content.

\section{REFERENCES}

[1] Mishra A. A Study of the Factors Influencing Cultural Tourists' Perception and Its Measurement with Reference to Agra. The IUP Journal of Marketing Management. 2013; 12(4):42-64

[2] Dongfeng L. Major sports events, destination image and intention to revisit from the foreign tourist's perspective. International Journal of Sports Marketing \& Sponsorship. 2013; 14(3):23-34.

[3] Herstein R, Berger R. Cities for sale: How cities can attract tourists by creating events. The Marketing Review. 2014; 14(2): 131-144.

[4] Herstein R. The thin line between country, city and region branding. Journal of Vacation Marketing. 2012; 18(2): 147-155.

[5] Bowdin G, Allen J, Harris R, McDonnell I, O'Toole W. Events Management. Routledge; 2012.

[6] Kaplanidou K. The importance of legacy outcomes for Olympic Games four summer host cities residents' quality of life: 1996-2008. European Sport Management Quarterly. 2012; 12:397-433.

[7] Agha N, Fairley S, Gibson H. Considering legacy as a multidimensional construct: The legacy of the Olympic Games. Sport Management Review. 2012; 15:125-139.

[8] Li X. R, Kaplanidou K. The impact of the 2008 Beijing Olympic Games on China's destination brand: A US-based examination. Journal of Hospitality and Tourism Research. 2013; 37:237-261.

[9] Kim J, Ho Kang J, Kim Y-K. Impact of Mega Sport Events on Destination Image and Country Image. Sport Marketing Quarterly. 2014; 23:161-175.

[10] Olsen C.S. Re-thinking festivals: A comparative study of the integration/marginalization of arts festivals in the urban regimes of Manchester, Copenhagen and Vienna. International Journal of Cultural Policy. 2013; 19(4):481-500.

[11] Herstein R, Jaffe E.D, Berger R. Forever young - How can a branding destination strategy rejuvenate a city image? The case of Tel Aviv. Journal of Urban Regeneration and Renewal. 2013-14; 7(3): 211-223.

[12] Sarajevo Film Festival. About the festival. (Jun 04, 2017). Available at: http://www.sff.ba/stranica/o-festivalu.

[13] Nihat Kamil A. Festival visitors' satisfaction and loyalty: An example of small, local, and municipality organized festival. Tourism. 2012; 60(3): 255-271. 